Portland State University

PDXScholar

\title{
A Methodological Review of Resilience Approaches for Coral in the Face of Climate Change
}

\author{
Gabriella L. Martinez
}

Portland State University

Follow this and additional works at: https://pdxscholar.library.pdx.edu/honorstheses

Part of the Aquaculture and Fisheries Commons

Let us know how access to this document benefits you.

\section{Recommended Citation}

Martinez, Gabriella L., "A Methodological Review of Resilience Approaches for Coral in the Face of Climate Change" (2020). University Honors Theses. Paper 893.

https://doi.org/10.15760/honors.914

This Thesis is brought to you for free and open access. It has been accepted for inclusion in University Honors Theses by an authorized administrator of PDXScholar. Please contact us if we can make this document more accessible: pdxscholar@pdx.edu. 
A Methodological Review of Resilience Approaches for Coral in the Face of Climate Change

\author{
by
}

Gabriella Martinez

An undergraduate honors thesis submitted in partial fulfillment of the requirements for the degree of

Bachelors of Science in

University Honors

and

Biology

Dr. Annie Lindgren

Portland State University

2020

\title{
$\underline{\text { Question }}$
}


What methods being developed to help corals become more resilient to the effects of climate change?

\section{Introduction}

Coral reefs are essential ecosystems that benefit both marine and human life through economic, environmental, and educational means. They contribute to ocean health and beauty, and their loss would have devastating ripple effects felt throughout the world.

\section{Biodiversity}

Many forms of marine life rely on coral reefs for habitat, shelter, spawning grounds, and food. Despite occupying a small proportion of earth, they have an important role in the marine environment. "Coral reefs cover less than 0.5 percent of the earth's surface but are home to an estimated 25 percent of all marine species" (Storlazzi, 2019). Coral reefs, often called "rainforests of the sea," are communities of life, as many types of fish, sharks, worms, turtles, sponges, jelly fish, and others make their home in the reef. "Coral reefs support more species per unit area than any other marine environment, including about 4,000 species of fish, 800 species of hard corals and hundreds of other species" (NOAA, 2020). These fish use coral communities as both spawning grounds and nurseries, and fish populations would be negatively impacted by the continuing decline of coral reefs. A decline in fish populations would unfortunately lead many humans around the world to lose a vital economic and food resource.

\section{Economic Value}

Coral reefs are not only a major source of biodiversity, but also an important resource for millions of humans. "In developing countries, coral reefs contribute about one-quarter of the total fish catch annually, providing critical food resources for tens of millions of people" (Jameson 
et al., 1995). The loss of these reefs and subsequent fish populations could lead to food shortages, as these tens of millions of people would have to struggle to find a replacement for this food source.

There are also many jobs and businesses in the tourism and fishery industries that rely on the continued health of the reef for their livelihoods. Spalding (2017) performed a recent assessment on the economic contribution of worldwide coral reefs. Drawing on data from over 100 countries and territories around the world that are home to coral reefs, he showed that: "coral reefs represent an economic value to the world of approximately $\$ 36$ billion dollars annually" This number includes the money that comes from on-reef industries like fishing, but also the money that comes from reef-adjacent tourism business ventures including hotels, restaurants, airlines, and diving gear suppliers. There is definitely inherent value in reefs for the amount of marine life and diversity that they support, but there is also economic value to be gained from preserving coral.

Coral reef ecology

Corals are a member of the phylum Cnidaria, and are animals that are often misclassified as plants. A coral reef is not a singly individual, but instead are made of a community of hundreds to thousands of individual coral polyps. These polyps will attach to either rocks on the sea floor, or the skeletons of dead polyps. Single polyps grow and spread to form these massive reefs over time. Over time, this cycle of growth, death, and new attachment will form the large structures commonly associated with coral reefs. This cycle is also what allows coral colonies to live for a long time. "Most reefs are about 5,000 to 10,000 years old, while each coral colony has a significantly smaller lifespan of hundreds of years" (Simmons, 2019). It is also what allow coral 
to grow so large. The Great Barrier Reef in Australia is the largest coral reef system, at over 1,500 miles long (Ross, 2018).

Corals live in nutrient poor waters and thus, would starve without their symbionts, the photosynthetic algae that live in their tissues. These algae are dinoflagellates from the genus Symbiodinium, called zooxanthellae. "These algae live in coral tissues in extremely high densities (greater than $10^{\wedge} 6 \mathrm{~cm}^{\wedge}-2$ ) and provide up to $90 \%$ of a coral's nutritional requirements" (Muscatine et al. 1977). In addition to providing nutrients, the zooxanthella are also what give coral their bright and diverse colors. "Zooxanthellae supply the coral with glucose, glycerol, and amino acids, which are the products of photosynthesis. The coral uses these products to make proteins, fats, and carbohydrates, and produce calcium carbonate" (Barnes, et al, 1987) "In fact, as much as 90 percent of the organic material photosynthetically produced by the zooxanthellae is transferred to the host coral tissue" (Sumich, 1996). The zooxanthellae also help coral produce oxygen and remove wastes. Both the algae and coral benefit from this mutualistic symbiosis. The coral produces compounds that the zooxanthellae need for photosynthesis and provide them with a safe environment to colonize. In addition, there is a cycling of nutrients between the Symbiodinium and the coral.

Coral need cool and clear water so that the zooxanthellae can continue to live and grow in coral tissues. If these conditions are not met, and water becomes too clear or polluted, zooxanthellae become stressed and expel, leaving the coral to starve now that $90 \%$ of its food and nutrition input source is gone.

\section{Coral Reef Stressors}


In recent decades there has been a massive decline in corals, prompting researchers to try and understand what stressors are most severely impacting coral communities, both natural and anthropogenic. There are many natural stressors of coral, "Including predation, competition, storms and also natural disease outbreaks" (Sheridan, 2013). These are all stressors that coral have had to face for thousands of years. But the increasingly sharp decline in coral populations cannot be contributed to natural causes alone, prompting many studies on coral communities around the world. Unnatural stressors that have only been introduced in recent decades, like water pollution, ocean warming, and ocean acidification have been found as contributing to their rapid decline (Sheridan, 2013).

Corals are naturally sensitive to temperature fluctuations. Researchers looked into the mass coral bleaching events of the last 30 years and found "The cause of coral death in these cases was due to increases in both local and regional seawater temperatures which stress the symbiotic relationship between the coral animal and its endosymbiotic alga, the dinoflagellate Symbiodinium microadriaticum” (Antonelli et al. 2016; Hughes, T. P.,1994; Middlebrook et al., 2008). The increasing water temperatures are causing coral to become stressed, and zooxanthellae are expelled. "This eviction of zooxanthellae causes "bleaching" of the coral holobiont because pigmentation in hermatypic corals is generally derived from the zooxanthellae, not pigment in the coral tissue" (Antonelli et al. 2016). Once the zooxanthellae are expelled, only the white coral skeleton is left, and it is "bleached."

\section{Coral Bleaching}


Coral bleaching occurs when the symbiotic association between corals and zooxanthellae is broken, often thought to be caused by increased temperatures (Douglas, 2003). While it is thought that corals most likely expel their zooxanthellae when stressed (Brown, 1997), this interaction is not fully understood. Because this algae is what give coral its color, its departure leaves the coral a white "bleached" color. Because zooxanthellae provide up to $90 \%$ of nutrients to corals (Sumich, 1996), bleaching events can lead to coral starvation. Corals can survive a bleaching event, and a bleached coral doesn't necessarily indicate a dead coral. If the stressor is removed or limited, zooxanthellae may return and the coral can return to full health. If the stressor is not removed, the coral will starve from lack of zooxanthellae to provide oxygen and nutrients, or die due to starvation increasing coral disease susceptibility.

\section{Research Motivation}

Half of the world's coral populations have died in the last 30 - 50 years due to coral bleaching (Hughes et al., 1994; Gardner et al., 2003). Estimates based on current models of decline project that by the year 2050, we will have lost $90 \%$ of coral populations (Burke, et. al, 2011). This will negatively impact many forms of marine life that rely on reefs for their food supplies, breeding, and nursery grounds. There could be catastrophic ripples in the ecosystem if this vital marine habitat is not able to fight back. It will also impact the millions of people who depend on reefs for a living in areas such as tourism, fishing, industry, and food.

For this paper, I will focus on evaluating three different approaches to coral reef conservation that are being tested in the lab and in the field: 1) Resilience Based management, 2) Aquaculture and 3) Assisted gene flow/evolution. I will 1) describe background information related to these methods, 2) summarize how successful they have been to date, and 3) address any backlash or concern that the public or scientific communities have made concerning these efforts. 


\section{$\underline{\text { Literature Review }}$}

We know that coral populations around the globe are in significant decline (Hughes et al., 1994; Gardner et al., 2003; Burke, et. al, 2011), so researchers are working to understand the potential for corals to become more resistant to coral reefs. There is some evidence that corals can build up natural resistance over time. For example, researchers in Hawaii (Coles et al. 2018) recently demonstrated that coral are very slowly building up resilience through naturally occurring processes. They looked at different coral species, including Montipora capitata, Lobactis scutaria, and Pocillopora damicornis.to see if there was any difference in thermal tolerance now vs 50 years ago, in 1970 when the first mass mortality events began happening. They compared using threshold temperatures from the 1970's and average modern temperatures. All three species showed "statistically higher calcification rates survivorship, and lower mortality at $31^{\circ} \mathrm{C}$ " (Coles et al. 2018). Overall the study showed that current corals exposed to 1970's conditions showed a relative decrease in mortality, compared to what was observed in the observed 1970's mortality rate. Researchers concluded current corals are more resilient, as there was a $17 \%$ decrease in mortality for modern coral. Studies like this one show that coral are capable of acclimating and adapting to higher ocean temperatures, but the process is extremely slow. Human caused temperature changes will quickly outpace the corals natural ability to adapt.

While there have been some protective and preventative measures put in place to help curb the decline in coral populations (Mulhall, 2009), there is agreement in the marine science community that current relief efforts will not be enough to prevent the continued decline of coral populations (Maher et al. 2019). Global temperatures are rising too fast, and coral cannot naturally evolve fast enough to keep up with these temperature spikes (Coles, et al. 2018). A National 
Science Foundation study of factors that cause corals' stress suggests that localized attempts to curb pollution on reefs won't save them without a worldwide effort to reduce global warming (Maher et al. 2019). However, there is also a general consensus that it is not too late to save coral reefs, and if action is taken now, then preservation is possible. While some want to work to increase protection of coral from local threats by building protected marine areas (Mcclanahan et al., 2006), many argue we need to be taking more proactive measures to preserve coral reefs (Maher et.al, 2019).

One of the proposed methods being tested is resilience based management theory, which involves finding activities harmful to the ecosystem and finding ways to reduce these actions and therefore their effects. It's purpose is to decrease negative factors and increase positive factors to improve ecosystem health as a whole.

Another of the proposed projects to increase coral resiliency is Aquaculture, which has been used successfully in the past for non-coral related projects (Mercier et al., 2013). Aquaculture involves cultivating freshwater or saltwater organisms under controlled conditions, where intervention in the form of stocking, feeding, or protection often takes place. It is a method that has been used to help increase many fish and plant populations (Bostock 2010). Researchers are trying to find a way to translate this successful method over to help increase decimated coral populations.

Another method being developed and tested is a lab-based proactive approach that involves either assisted gene flow or assisted evolution. These overlapping methods take a more active approach that involves increasing gene flow, hybridization and laboratory experiments to stress corals and/or their symbionts to better understand and possibly build, resilience to thermal 
stress. Much of this type of research is still in the planning and theoretical stages, as there are concerns raised about modifying nature.

\section{Current Research Projects}

\section{Resilience Based Management Theory}

Researchers in Hawaii investigated using resilience-based management theory to help coral recover from bleaching events. Resilience-based management theory involves increasing, or at the very least maintaining, the resilience of whole ecosystems against global warming. It involves finding "levers" which are defined as actions that will have a direct impact on resilience or reduce reef vulnerability" (Chung, 2019).

Overall, researchers examined 12 different levers that Hawaii had put into action, and identified the effectiveness of each. These 12 levers were broken into six basic categories: "1) spatial planning, 2) fisheries rules, 3) gear rules, 4) aquaculture, 5) land-based pollution mitigation and 6) enforcement" (Chung, 2019). Researchers collected data from 100 past studies done on individual levers and did a systematic review on which levers had shown greater degrees of resistance and recovery. Results showed that there was evidence that spatial planning, fisheries rules and enforcement strategies had the most positive impact on coral resistance and recovery. Regions that had employed these methods showed evidence for resistance, as coral who had these techniques implemented were more resistant to bleaching than their counterparts, and also showed greater amounts of coral recovery after bleaching events. There was also evidence that adjusting levers like gear restrictions, aquaculture techniques, or mitigation strategies increased both resistance and recovery, but not to the degree of the other three levers. This type of research 
is helpful to coral reef managers in Hawaii, so they can adapt strategies that have proven effective.

Resilience-based management theory is good in that it takes a broader approach to understanding the problem, but it is also hard to implement because the type of management needed is going to vary by region. There is no guarantee that the steps being put forward in Hawaii are going to work in barrier reefs located in Australia and India, because ecological factors vary, and because there may be different legal issues, or policy capacity. However, this type of research shows that it is possible to do local-scale interventions based on global-scale recommendations. From this type of research, a new and more efficient process can be discovered and implemented, and put resilience-based management theory into practice.

\section{$\underline{\text { Aquaculture }}$}

There are two types of coral aquaculture currently in use. The first type is commercial aquaculture, which involves general techniques in closed tanks that are currently used (Ellis, 1999) to farm coral for aquarium sales. The second type is more challenging, and involves applying these farming aquaculture techniques to restore coral reefs in the ocean.

Coral aquaculture used for commercial purposes involves farming soft coral for the aquarium trade using fragmentation techniques, where a fragment of coral is removed from the parent colony to form a new colony (Ellis, 1999). This type of aquaculture is important because coral stock are bred and removed for customers on-site in a controlled environment. It means that wild coral in the ocean, which are already struggling under mass bleaching events are left alone. If aquaculture could be more broadly applied to further take the strain off of natural corals, it 
could help combat increasing coral mortality rates. Presently, it is estimated that coral aquaculture represents less than $20 \%$ of the global coral trade (CITES 2016). This means that coral traders are still taking around $80 \%$ of their product from the oceans, whose populations are already struggling.

Applying farming techniques to coral reef restoration involves farming coral in a safe environment and eventually transplanting them onto reefs. This type of restoration has a lot of potential and is being explored as an option in many countries. In Madagascar, Acropora nasuta and Seriatopora caliendrum samples were collected from the field and investigated to see if there was potential for restoration aquaculture (Todinanahary et al., 2016). Madagascar has used aquaculture techniques in the past with success; they successfully launched aquaculture with seaweed and sea cucumber farming (Conand et.al, 1997). To see if aquaculture was a viable method, researchers had to determine if aquaculture helped coral survival rates and if the process was cost effective. To do this, survival and growth rates of coral were tracked through different farming sites. The farming site with the highest survival rates was then used going forward (Todinanahary et al., 2016). The results of this study found that coral survival rate was high, and it was a technical and environmentally feasible way to help coral survive. But the researchers concluded that the process was too expensive with the removal, growth, monitoring daily, and eventual transplantation, and that it wasn't economically feasible since ongoing financial support was not secured. It would be better if some were sold and some were transplanted so that there was enough money coming in to continue the process, so that the economic benefits could support the environmental restoration .

However, there are some problems that have arisen with coral aquaculture. Coral are raised in dense clusters with each other, making them particularly vulnerable to specific diseases 
since virulence and communicability of pathogens have been shown to increase with host density" (Sheridan, et. al 2013). Although this is a problem for both in situ and ex situ colonies, in situ are particularly vulnerable since natural marine diseases have been on the rise (Ward, 2004) This is worrisome because any disease outbreak can result in loss of the entire colony. While many studies have been done on natural coral outbreaks, there have not been many studies of disease in coral aquaculture, and therefore the causes and effects of diseases, as well as how to treat them is lacking (Sweet, 2011). If coral aquaculture is to be a viable way for increasing coral resiliency, there will need to be a lot more research on coral diseases so that mass colony wipeouts can be avoided when disease breaks out, which it is wont to do in such close quarters.

\section{$\underline{\text { Assisted Gene Flow and Assisted Evolution }}$}

While resilience management theory involves trying to proactively protect the whole ecosystem, and aquaculture involves growing corals in a controlled setting, a third more drastic research approach involves using adaptive gene flow and adaptive evolution to understand and proactively increase coral resilience to thermal stress. These methods utilize laboratory experiments and direct coral transplantation to speed up the rates of adaptation and resilience in corals.

Assisted gene flow involves taking heat adapted corals and moving them to cooler parts of the reef to build future warming resistance by increasing the potential for offspring to crossbreed during spawning cycles. This could be done through either assisted larval dispersal or through assisted adult migration (Anthony et al., 2017; Oppen et al., 2015). One example of an area where assisted gene flow is being tested is the Great Barrier Reef in Australia. Studies have indicated that corals further towards the Northern end of the reef are naturally adapted to living 
in about $3^{\circ} \mathrm{C}$ higher temperatures than those further South (Bainbridge, 2017). Using this information, scientists could theoretically increase warming resistance in Southern corals by moving in heat adapted stock, speeding up a process that would take many years if it were allowed to happen naturally through normal spawning and distribution of larvae through currents.

The term assisted evolution refers to a range of approaches that involve active intervention to accelerate the rate of naturally occurring evolutionary processes. In coral, assisted evolution would come in the form of hybridizing different corals by mating "strong" heat stressed corals with "weaker" less resilient corals (Oppen et al., 2015). This type of cross-breeding is not traditionally used for conservation biology, but is common in farming and commercialization, such as hybridizing food crops to select for stronger and more temperature resistant crops (NewellMcgloughlin, 2008). There are concerns that this could compromise a reef's genetic diversity, and that stronger ethical regulations are needed (Filbee-Dexter, et al., 2019). Despite the pushback, studies on the characteristics of coral hold them to be good candidates for assisted evolution, and scientists theorize that this method could help coral develop the capacity to adapt at a pace matching the current increasing temperatures (Oppen, et.al, 2015).

Oppen et al., (2015) are one of the teams studying how to use assisted evolution to build more resilient coral that can withstand heat waves. When coral spawn during a once a year event, Van Oppen and her team gather genetic material in the form of thousands of bundles of eggs and sperm that is taken to the lab for further study of cross breeding potential (Cornwall, 2019). Using these preliminary findings, Van Oppen hypothesized four different methods studying and potentially increasing coral resiliency using assisted evolution (Oppen et al., 2015). Three of the approaches involve changes to the coral themselves, and the fourth involves changing the algal symbiont. 


\section{1) Inducing Acclimatization}

The first method involves using assisted evolution to expose natural coral stock to thermal stress and induce "preconditioning acclimatization (i.e., within generations) and transgenerational acclimatization (i.e., between generations) through epigenetic mechanisms sensu strictu" (Van Oppen, 2015). The idea is to slowly acclimate corals through controlled exposure to increasing temperatures, a sort of heat vaccine so that coral have time to build a heat immunity within a single coral generation. Putting this into practice would involve targeting traits that have high heritability. In other words the trait allowing the corals to survive high heat would need to have a genetic basis.

This type of acclimatization was tested at Heron Island Research Island in Australia (Middlebrook et al., 2008), where researchers collected branches of the coral species Acropora aspera and its symbiont Symbidonium from its natural reef habitat. Half of these coral branches were put in heated tanks where the temperature was elevated to $31^{\circ} \mathrm{C}$ over a 48 hour period. The other half, which acted as the control group, were left in unheated tanks that were left at the $27^{\circ} \mathrm{C}$, which is the local average ocean temperature. All coral were then left alone for the next two weeks. Researchers then exposed both groups of coral to $34^{\circ} \mathrm{C}$ for 6 days, simulating a bleaching event. It was found that the symbionts in the control corals dropped by approximately $40 \%$, but those in the heat-stressed group had the density of their Symbidinium colonies remain the same (Middlebrook et al., 2008). Authors concluded that the corals showed less stress after a pre-heatwave heat exposure.

This is a non-invasive and rather simple method that has yielded positive results in one study (Middlebrook et al., 2008), but it has several problems that make it hard to implement on a large scale. One problem is that it would be challenging to find a way to do this pre-stressing 
event to enough coral to make a real impact on global populations of coral. Another problem, that the authors (Middlebrook et al. 2008) point out, is that even with the controlled heat stress, there is only a small temperature range that coral can live in, and while the heat stress can help coral better survive bleaching events under current temperatures, it will not be enough to help them survive future projected temperatures from ever increasing global warming.

\section{2) Modification of Microbial Communities}

The second method involves using assisted gene flow by actively modifying "the community composition of coral-associated microbes (eukaryotic and prokaryotic)" (Oppen et al., 2015). As previously discussed, coral have a mutualistic relationship with the dinoflagellates in the genus Symbiodinium. These Symbiodinium are diverse, and so are their functions. Studies done on zooxanthellae have shown that there are eight different phylogenetic clades, A-H, with each clade containing many different species (Mieog et al., 2007). While most coral seem to only associate with a single zooxanthellae type, molecular studies have shown these partnerships to be more flexible than previously thought, with different hosts and symbionts showing varying degrees of specificity in their associations (Baker, 2003).

For example, Van Oppen and her team tested whether the presence of different types of Symbiodinium can make a host more or less susceptible to environmental disturbances (Berkelmans et al, 2006) Using Acroporal millepora, the researchers sampled 22 colonies from the Southern portion of the Great Barrier Reef, and another 22 were taken from the Northern portion, and transplanted the colonies to the center of the reef, where temperatures average around $1^{\circ} \mathrm{C}$ higher than the cool waters they were transplanted from. To determine if the presence of a certain type of Symbidinium had greater thermal tolerance, the types of zooxanthellae associated with the different colonies were identified using fluorescence and used the internal transcribed 
spacer gene (ITS1) to genotype. Researchers needed to know what types of zooxanthellae were associated with the different coral colonies. Berklemans et al., (2006) were able to draw several conclusions from this study. They found that coral colonies with Symbiodinium types C and D had an increased thermal tolerance, and that type D was the most thermally resistant type. The tolerance gained by type D Symbiodinium coral in the study increased thermal tolerance by around $1-1.5^{\circ} \mathrm{C}$ (Berkelmans et al, 2006). This study showed there is potential to help coral acclimatize by introducing different Symbiodinium to impart greater heat resistance. Decreasing specificity and allowing for a greater range of potential symbiotic inhabitants could help coral increase heat resistance. However, no compelling evidence exists to suggest adult corals are able to establish a stable symbiosis with novel Symbiodinium types, meaning that any work done with transferring Symbiodimium would have to be done during early coral life while coral are still juvenile and able to accept different types of Symbiodinium (Coffroth et al., 2010). So there is only a small window of opportunity, and existing adult communities of corals would not benefit from this type of assisted evolution. Therefore, it would take several years while the experimented coral matured before effects could really start to take effect.

While this second form of assisted evolution has potential going forward for future generations of coral, this in itself is not a complete solution. While it is significant that this research provides a way for coral to adapt exponentially faster than they would in nature, it would most likely only be a delay, as predicted sea surface temperatures over the next hundred years show higher increases in temperature than the $1-1.5^{\circ} \mathrm{C}$ buffer this would give coral (NOAA, 2016). The authors do acknowledge that this won't save coral by itself but put forth the idea that it could buy time while humans work to reduce greenhouse emissions.

\section{3) Selective Breeding}


The third method involves using assisted evolution to selectively breed corals to "generate certain genotypes exhibiting desirable phenotypic traits" (Van Oppen et al., 2015). This would involve mixing gene pools from either the same or different species, also known as infraspecific and interspecific hybridization, respectively. Interspecific hybridization occurs when scientists take two distinct species and hybridize them. Research has focused on interspecific hybridization, because of the increased potential for gene flow. One common example is the "leopon" which is obtained by crossing a male leopard and a female lion. Interspecific hybridization has been used in other research (Brasier et al., 1999; Schwenk et al., 2008), mainly with scientists using it to increase genetic diversity and thus adaptive potential via hybridization. A benefit to hybridization is the increase in genetic diversity to the population, which allows for more combinations that may help the individual acclimate and the population adapt over time to an ever-changing environment.

Scientists are exploring this interspecific hybridization as a way to help corals in the face of global warming. This hybridization could be used to select for phenotypic traits like high thermal tolerance, or it could be used to increase coral genetic variability and give natural selection something more to act on (Oppen et al., 2015) A study conducted in the Australian Institute of Marine Sciences (Chan et al., 2018) took two Acropora species and hybridized them. The species hybridized were (1) an Acropora tenuis $\times$ Acropora loripes cross, and (2) an Acropora sarmentosa $\times$ Acropora florida cross. Sperm-egg bundle samples from all three species were collected from a section of the Great Barrier Reef, called Trunk Reef, and then placed in higher thermal waters. The various hybrid crosses were then compared to purebred controls made in the lab to see test for enhanced fitness and resilience. Fitness was measured using the four different criteria: survival, recruit size, Symbiodinium uptake, and photochemical efficiency. Overall, the 
study showed that hybrids have a higher climate resilience than the species that were purebred. The Acropora sarmentosa $\times$ Acropora florida cross showed a $12-22 \%$ higher survival rate and were larger than both of their parent species. This is good news. All hybrids were either equal to their purebred parents or better. This means that interspecific hybridization is a possibility.

Another testament to the possibility of interspecific hybridization occurred naturally in the Caribbean when the F1 hybrid A. prolifera was first observed. It is intermediate in its morphology to Acropora palmata (elk-horn coral) and A. cervicornis (stag-horn coral). Researchers compared fitness levels of this hybrid and parent species, and results seemed to favor the effectiveness of interspecific hybridization. "Hybrids were not found to be inferior to the parental species at any examined life history stage, and in a few cases hybrid viability exceeded the parental species" (Fogarty, 2012).

There are several concerns with interspecific hybridization. First, we do not know the long term effects of creating a more resilient species. It could be that the engineered coral will outperform and dominate wild coral and could further stress them as well. This could alter ecosystem dynamics and cause unintended ripples through the many forms of life that depend on the coral reefs. A second problem with transplanting coral from other areas is an increased risk of importing harmful pathogens. So, while the increase in hybridization may produce helpful phenotypic traits leading to increased reef resiliency, so is the possibility of a harmful mutated disease that could put struggling coral under further stress. Lastly, much more data needs to be collected, including testing over several generations of coral to make sure the hybrids have high enough fitness levels to be a viable option. Unfortunately, this type of testing is very slow going, as these coral species all take 3-7 years to reach reproductive maturity (Chan et al., 2018). It 
could be years before its proven effective enough for field work, which is time coral species do not have, as their population numbers dwindle with every year.

\section{4) Symbiodinium Evolution}

The fourth method involves using assisted evolution to evolve algal symbionts in the laboratory through "mutagenesis and/or selection" (Oppen et al., 2015). Researchers work to make Symbiodinum strains more heat tolerant by exposing them to environmental heat stress in the lab, and by exposing them to mutagens to increase somatic mutations (Oppen et al., 2015). Laboratory-based genetic adaptations of other asexually reproducing algae has been examined. For example, populations of the calcifying photosynthetic algae Emiliania huxleyi were exposed to increased concentrations of $\mathrm{CO}_{2}$. Within 500 asexual generations, E. huxleyi that were exposed to the $\mathrm{CO}_{2}$ had higher growth and calcification rates than the controls not exposed to $\mathrm{CO}_{2}$ (Lohbeck et al., 2012). Researchers could theoretically apply a similar strategy with Symbiodinium to see if they could select for more resilient symbionts, especially given their short generation times.

This type of mutagenesis has been successful in enhancing the micro algae Chlorella sorokiniana. Researchers wanted to increase the luteinizing productivity of the algae, and used Nmethyl-N'-nitro-nitrosoguanidine (MNNG) as a mutagen. The resulting C. sorokiniana mutant had double the lutein yield of the non-mutated micro algae controls (Cordero et al., 2011). The successful mutagenesis of $C$. sorokiniana lays the theoretical foundation for Symbidinium mutagenesis as a possible solution, but lab testing is in the early stages (Oppen et al., 2015).

Researchers are looking at applying similar methods to Symbiodinium to determine if they would be useful in a different system. No solid findings have been published. If researchers can translate results over, a more resilient Symbiodinium would be helpful in increasing resiliency in its symbiotic partner. 


\section{$\underline{\text { Time Constraints }}$}

A problem that applies to all the different types of assisted evolution considered, is that there is no easy way of knowing the long term effects of these types of manipulations on future generations of coral. This is not something that is simple to test either. For example, the Acropora aspera tested for preconditioning acclimatization have to wait a few years before they can breed. "The characteristic colony size at maturation usually corresponds to a minimum puberty age of 1-3 years" (Hall, 1996). It could take years and maybe even decades before enough generations have been monitored and cleared to be safe for field introduction. This is time that the dwindling coral population do not have.

\section{$\underline{\text { Conclusion }}$}

The extreme thermal stress caused by human-induced climate change is causing mass mortality of coral, which are unable to keep pace with the speed of changes seen in the world's oceans. One option is to work to manage the entire ecosystem through resilience-based management theory (Chung et al., 2019), but it has the pitfall of not being an easily solved or implemented strategy, as different regions around the world will have different requirements and legal regulations. Alternately, Aquaculture has the potential to farm enough coral to restore the oceans' reefs, but the monetary cost of this approach to raise, feed, protect, and transport coral is high. Lastly, researchers focused on gene flow and assisted evolution studies, which have the potential to make a significant difference, but are more invasive methods that require long term observation before implementation is feasible (Middlebrook et al. 2008; Oppen et al., 2015).

Hoegh-Guldbert et al. (2018) argues that caution needs to be exercised when undertaking projects using these new technologies, as we do not yet have scientific understanding of potential adverse outcomes. Other researchers (Anthony et al., 2017; Rau et al. 2012) contend 
that if coral are to increase resiliency enough to meet the predicted heat spikes in the upcoming years, human intervention is definitely needed, but refer to assisted evolution and other resilience based techniques as "opportunities of last resort," as the real problem is the increasing emissions of greenhouse gases.

It is my opinion that using all three methods (management, aquaculture, and assisted evolution/gene flow) in combination is required to help save coral reefs. There needs to be more push for proactive conservation, such as policy that reduces greenhouse gases, and puts a curb on global warming (Rau et al., 2012). Aquaculture can help to reduce stress on coral fisheries and may prove useful for breeding some coral species that could be transplanted back into the natural system (Chung et al., 2019). Lastly, it is important that assisted evolution and gene flow approaches are continually researched as viable means of speeding up the evolution of coral resiliency in response to thermal stress. (Middlebrook et al., 2008; Oppen et al., 2015) It is important to continue to also put effort into proactive research studies that work to help build coral resilience because we know that, even with more proactive measures in place, thermal stress will continue to be an issue for coral reefs (Burke et al., 2011). The loss of coral and coral reefs would be devastating, causing a massive decline in the biodiversity marine life as we know it, as one quarter of the world's annual fish catch come from coral reefs (Storlazzi, 2019).

The loss of breeding and eating grounds could theoretically cause a decline in fish populations, reducing an important and vital food source to many people around the world, and thousands of people in the tourism and fishing industries would lose their jobs, such as reef adjacent businesses like hotels and restaurants (Jameson, 1995).

It is my opinion that now is the time for daring and risky. The world has lost $80 \%$ of its coral populations. Coral reefs are on their last leg, and future projections of warming show no 
hope of recovery. It is only going to get worse. I think that the interspecific hybridization of different coral species in order to make a new and superior species is the type of current effort that could do the most good. Breeding coral that are stronger and more heat resistant by combining different phenotypic traits across species has a lot of potential to be a viable solution. It does have its risks, but at this point the risks seem to cost less than doing nothing.

\section{Annotated Bibliography}

Anthony, K., Schaffelke, B., Bay, L. K., \& Oppen, M. van. (2017, October 11). Turns Out The Great Barrier Reef Can Actually Heal Itself, But We Have to Help It. Retrieved October 15, 2019, from https://www.sciencealert.com/australia-s-great-barrier-reef-repair-help-science-climate-change-warming-bleaching.

- Research being done on assisted gene flow and assisted evolution to produce more bleachingresistant corals

Anthony, K., Bay, L. K., Costanza, R., Firn, J., Gunn, J., Harrison, P., ... Walshe, T. (2017). New interventions are needed to save coral reefs. Nature Ecology \& Evolution, 1(10), 1420 1422. doi: $10.1038 / \mathrm{s} 41559-017-0313-5$

- Research being done on horizontal gene flow and assisted evolution to produce more bleaching-resistant corals

Antonelli, P. L., Rutz, S. F., Sammarco, P. W., \& Strychar, K. B. (2016). Evolution of symbiosis in hermatypic corals: A model of the past, present, and future. Nonlinear Analysis: Real World Applications, 32, 389-402. doi: 10.1016/j.nonrwa.2016.05.004

- The survival of scleractinian corals in the projected hyper-tropical zone of the Earth is dependent upon adaptations to occur prior to temperatures surpassing predicted critical level

- Those species of corals which are able to adapt to changing temperature regimes on the earth will represent the new members of coral communities

Bainbridge, Scott (2017) Temperature and light patterns at four reefs along the Great Barrier Reef during the 2015-2016 austral summer: understanding patterns of observed coral bleaching, Journal of Operational Oceanography, 10:1, 16-29, DOI: 10.1080/1755876X.2017.1290863

- The reefs to the north had a greater number of days above the empirical bleaching thresholds and a greater number of days above the two and three SD limits (Table 2). Maximum temperatures were also recorded later in the northern reefs (mid-March 2016) than in the southern reefs (early February 2016).

Baker, Andrew C. "Flexibility and Specificity in Coral-Algal Symbiosis: Diversity, Ecology, and Biogeography Of Symbiodinium.” Annual Review of Ecology, Evolution, and Systematics, vol. 34, no. 1, 2003, pp. 661-689., doi:10.1146/annurev.ecolsys.34.011802.132417. 
Barnes, R.D. 1987. Invertebrate Zoology; Fifth Edition. Fort Worth, TX: Harcourt Brace Jovanovich College Publishers. pp. 92-96, 127-134, 149-162.

- Algal symbiosis

Berkelmans R, van Oppen MJH. The role of zooxanthellae in the thermal tolerance of corals: A 'nugget of hope' for coral reefs in an era of climate change. Proc R Soc B Biol Sci.

2006;273:2305-2312.

Bostock, John, et al. "Aquaculture: global status and trends." Philosophical Transactions of the Royal Society B: Biological Sciences 365.1554 (2010): 2897-2912.

- The importance of aquaculture, in statistics and number

Brasier, C. M., et al. "Origin of a New Phytophthora Pathogen through Interspecific Hybridization.” Proceedings of the National Academy of Sciences, vol. 96, no. 10, Nov. 1999, pp. 5878-5883., doi:10.1073/pnas.96.10.5878.

Brown, B. Coral bleaching: Causes and Consequences. Coral Reefs 16, S129-S138 (1997). https://doi.org/10.1007/s003380050249

Burke, Lauretta, et al. "Reefs at Risk Revisited.” World Resources Institute, Feb. 2011, https://www.wri.org/publication/reefs-risk-revisited.

- By the year 2050, we will have lost $90 \%$ of coral populations

Chan, W. Y., Peplow, L. M., Menéndez, P., Hoffmann, A. A., \& Oppen, M. J. H. V. (2018). Interspecific Hybridization May Provide Novel Opportunities for Coral Reef Restoration. Frontiers in Marine Science, 5. doi: 10.3389/fmars.2018.00160

- Investigated interspecific hybridization as a tool to develop coral stock with enhanced climate resilience by crossing two Acropora species

- Hybrids had higher survival and larger sizes

Chung, A., Oliver, T., Gove, J., Gorospe, K., White, D., Davidson, K., \& Walsh, W. (2019). Translating resilience-based management theory to practice for coral bleaching recovery in Hawai'i. Marine Policy, 99, 58-68. doi: 10.1016/j.marpol.2018.10.013

- Evaluates the effectiveness of interventions to make evidence-based decisions in order to translate resilience-based management theory into practice to manage coral reefs in Hawaii and beyond.

CITES, 2016 CITES, CITES Trade Database, CITES Secretariat (2016)

- Info on aquarium trade related to aquaculture

Coffroth MA, Poland DM, Petrou EL, Brazeau DA, Holmberg JC

PLoS One. 2010 Oct 7; 5(10):e13258.

Coles SL, Bahr KD, Rodgers KS, May SL, McGowan AE, Tsang A, Bumgarner J, Han JH. 2018. Evidence of acclimatization or adaptation in Hawaiian corals to higher ocean temperatures. PeerJ 6:e5347https://doi.org/10.7717/peerj.5347' 
- Study on whether Coral have increased resiliency as a whole since the first bleaching events began

- However, this level of increased temperature tolerance may not be occurring rapidly enough to escape the projected increased intensity of bleaching events, as evidenced by the recent 2014 and 2015 high coral mortality in Hawai'i (34\%) and in the tropics worldwide.

Conand C. and Rasolofonirina, R.. "Sea Cucumber Exploitation in the Toliara Region of SouthWest Madagascar.” Beche-De-Mer Infor. Bull, vol. 10, 1997, pp. 10-13

- aquaculture used on seas cucumbers

Cordero, Baldo F., et al. "Enhancement of Lutein Production in Chlorella Sorokiniana (Chorophyta) by Improvement of Culture Conditions and Random Mutagenesis." Marine Drugs, vol. 9, no. 9, 2011, pp. 1607-1624., doi:10.3390/md9091607.

Cornwall Mar, Warren, et al. "Researchers Embrace a Radical Idea: Engineering Coral to Cope with Climate Change." Science, 21 Mar. 2019, www.sciencemag.org/news/2019/03/researchersembrace-radical-idea-engineering-coral-cope-climate-change

Douglas, A. (2003). Coral bleaching-“how and why? Marine Pollution Bulletin, 46(4), 385-392. doi:10.1016/s0025-326x(03)00037-7

Ellis, Simon. "Farming Soft Corals for the Marine Aquarium Trade TROPICAL" Aquafarmer Information Sheet, Farming Soft Corals for the Marine Aquarium Trad, Aug. 1999, www.ctsa.org/files/publications/CTSA_1406316728562309351601.pdf.

Fidelman, P., Mcgrath, C., Newlands, M., Dobbs, K., Jago, B., \& Hussey, K. (2019). Regulatory implications of coral reef restoration and adaptation under a changing climate. Environmental Science \& Policy, 100, 221-229. doi: 10.1016/j.envsci.2019.04.016

- This study explores the regulatory implications of proposed restoration and adaptation interventions in the context of the Great Barrier Reef.

- Regulating innovative approaches such as assisted evolution

Filbee-Dexter, K., \& Smajdor, A. (2019). Ethics of Assisted Evolution in Marine Conservation. Frontiers in Marine Science, 6. doi: 10.3389/fmars.2019.00020

- Assisted Evolution raises challenging ethical questions because the intention is not to revert to a previous status quo, but to modify a community so that it survives better in the conditions we have created.

- We need stronger ethical regulations on applying assisted evolution techniques in marine conservation

Fogarty ND (2012) Caribbean acroporid coral hybrids are viable across life history stages. Mar Ecol Prog Ser 446:145-159. https://doi.org/10.3354/meps09469

Gardner, T., Côté, I., Gill, J., Grant, A., and Watkinson, A. (2003). Long-term region-wide declines in Caribbean corals. Science 30, 958-960. doi: 10.1126/science.1086050 
Hughes, T. P. (1994). Catastrophes, phase shifts, and large-Scale degradation of a Caribbean coral reef. Science 265, 1547-1551. doi: 10.1126/science.265.5178.1547

Hall, V. 1996. Reproductive strategies of modular organisms: comparative studies of reef-building corals. Ecology (Washington DC), 77, no. 3 (1996): 950-963.

Hoegh-Guldberg, Ove, et al. "Securing a Long-Term Future for Coral Reefs." Trends in Ecology \& Evolution, vol. 33, no. 12, 2018, pp. 936-944., doi:10.1016/j.tree.2018.09.006.

Jameson, S.C., McManus, J.W. and Spalding, M.D. 1995. State of the reefs: regional and global perspectives. ICRI Executive Secretariat Background Paper, May 1995. NOAA, 32pp

- Importance of reefs as food source

Levas, S., Schoepf, V., Warner, M. E., Aschaffenburg, M., Baumann, J., \& Grottoli, A. G. (2018). Long-term recovery of Caribbean corals from bleaching. Journal of Experimental Marine Biology and Ecology, 506, 124-134. doi: 10.1016/j.jembe.2018.06.003

- Initial bleaching response of Caribbean and Hawaiian corals and how they manage their C budgets is integral to recovery. Bleached Caribbean and Hawaiian corals that increase feeding rates or have high baseline high feeding recover more quickly.

Maher, Rebecca L., et al. "Multiple Stressors Interact Primarily through Antagonism to Drive Changes in the Coral Microbiome." Nature News, Nature Publishing Group, 2 May 2019, https://www.nature.com/articles/s41598-019-43274-8.

- A National Science Foundation study of factors that cause corals stress suggests that localized attempts to curb pollution on reefs won't save them without a worldwide effort to reduce global warming.

- A new study of factors that cause corals stress suggests that localized attempts to curb pollution on reefs won't save them without a worldwide effort to reduce global warming.

Manikandan, B., Ravindran, J., Vidya, P., \& Murali, R. M. (2016). Bleaching and recovery patterns of corals in Palk Bay, India: An indication of bleaching resilient reef. Regional Studies in Marine Science, 8, 151-156. doi: 10.1016/j.rsma.2016.07.005

- Studied coral reefs in India to see which coral were affected by bleaching more, and which had better recovery rates. Zero mortality was largely due to the shift in the species composition of corals towards the thermal tolerant ones.

- Could use this knowledge in the application of assisted evolution.

Mcclanahan, Timothy R., et al. "A Comparison of Marine Protected Areas and Alternative Approaches to Coral-Reef Management." Current Biology, vol. 16, no. 14, July 2006, pp. 14081413., doi:10.1016/j.cub.2006.05.062.

Mercier, A., and J.-F. Hamel. "Sea Cucumber Aquaculture: Hatchery Production, Juvenile Growth and Industry Challenges." Advances in Aquaculture Hatchery Technology, 2013, pp. 431-454., doi:10.1533/9780857097460.2.431. 
Middlebrook, R., et al. "The Effect of Thermal History on the Susceptibility of Reef-Building Corals to Thermal Stress." Journal of Experimental Biology, vol. 211, no. 7, Jan. 2008, pp. 1050-1056., doi:10.1242/jeb.013284

Mieog, J. C., et al. "Real-Time PCR Reveals a High Incidence of Symbiodinium Clade D at Low Levels in Four Scleractinian Corals across the Great Barrier Reef: Implications for Symbiont Shuffling." Coral Reefs, vol. 26, no. 3, June 2007, pp. 449-457., doi:10.1007/s00338-007-02448.

Mulhall, Marjorie. Saving the Rainforests of the Sea: An Analysis of ... 2009, www.researchgate.net/publication/42766104_Saving_the_Rainforests_of_the_Sea_An_Analysis_of_International_Efforts to_Conserve_Coral_Reefs.

Muscatine L, Porter J.W. Reef corals - mutualistic symbioses adapted to nutrient-poor environments. Bioscience. 1977;27:454-460. doi:10.2307/1297526

- The relationship between the animal like coral and their algae symbionts, broken down further

Newell-Mcgloughlin, Martina. "Nutritionally Improved Agricultural Crops." Plant Physiology, vol. 147, no. 3, July 2008, pp. 939-953. American Society of Plant Biologists , doi:10.1104/pp.108.121947.

NOAA "Corals." National Ocean Service Education: Corals, US Department of Commerce , 7 Jan. 2020, oceanservice.noaa.gov/education/kits/corals/coral07_importance.html.

- Numbers on the values of coral reefs on fishing, tourism, and how they work as natural buffers for people living on the coast.

NOAA "Climate Change Indicators: Sea Surface Temperature." EPA, Environmental Protection Agency, 17 Dec. 2016, www.epa.gov/climate-indicators/climate-change-indicators-sea-surfacetemperature.

Oppen, M. J. H. V., Oliver, J. K., Putnam, H. M., \& Gates, R. D. (2015). Building coral reef resilience through assisted evolution. Proceedings of the National Academy of Sciences, 112(8), 2307-2313. doi: 10.1073/pnas.1422301112

- The driving question behind this study is what can be done to help corals adapt to the changes caused by ocean acidification and global warming. The article argues that assisted evolution in the form of humans genetically modifying weaker stock by cross breeding them with stronger stock will help fight against these changes, but that further laboratory research is needed. There are concerns that there could be unintended physical and physiological consequences, such as the genetically modified coral turning into invasive species. The article uses past example of humans accelerating acclimatization processes for commercially relevant species, and the various successes that followed as evidence that this is a viable solution.

- This article is relevant as it pertains to my research of the methods that are being used to fight against coral bleaching, and it focuses specifically on assisted evolution, which is one of my focuses. The bibliography has several promising sources on different studies with the same question. 
Oppen, M. J., Gates, R. D., Blackall, L. L., Cantin, N., Chakravarti, L. J., Chan, W. Y., Cormick, C. , Crean, A., Damjanovic, K. , Epstein, H. , Harrison, P. L., Jones, T. A., Miller, M. , Pears, R. J., Peplow, L. M., Raftos, D. A., Schaffelke, B., Stewart, K. , Torda, G. , Wachenfeld, D. , Weeks, A. R. and Putnam, H. M. (2017), Shifting paradigms in restoration of the world's coral reefs. Glob Change Biol, 23: 3437-3448.

- Assisted evolution

- Advancement of methods for the large-scale rearing and deployment of coral stock manipulated for enhanced stress resistance are therefore urgently required.

Peters, Adele. "Scientists are speeding up evolution to build climate change resistance". 'Fast Company". Retrieved May 5, 2019.

Puisay, A., Pilon, R., Goiran, C., \& Hédouin, L. (2018). Thermal resistances and acclimation potential during coral larval ontogeny in Acropora pulchra. Marine Environmental Research, 135, 1-10. doi: 10.1016/j.marenvres.2018.01.005

- The results evidenced the occurrence of developmental thermal acclimation as a result of thermal pre-exposure of oocytes.

Rau, Greg H., et al. "The Need for New Ocean Conservation Strategies in a High-Carbon Dioxide World." Nature Climate Change, vol. 2, no. 10, 2012, pp. 720-724., doi:10.1038/nclimate1555.

- Discussion of invasive methods

Ross, Rachel. "What Are Coral Reefs?” LiveScience, Purch, 24 Sept. 2018, www.livescience.com/40276-coral-reefs.html.

Schwenk, Klaus, et al. "Introduction. Extent, Processes and Evolutionary Impact of Interspecific Hybridization in Animals." Philosophical Transactions of the Royal Society B: Biological Sciences, vol. 363, no. 1505, May 2008, pp. 2805-2811., doi:10.1098/rstb.2008.0055.

Sheridan, Christopher, et al. "Diseases in Coral Aquaculture: Causes, Implications and Preventions.” Aquaculture, vol. 396-399, 2013, pp. 124-135., doi:10.1016/j.aquaculture.2013.02.037.

- Research about disease and disease prevention in aquaculture colonies

Slavov, C., Schrameyer, V., Reus, M., Ralph, P. J., Hill, R., Büchel, C., ... Holzwarth, A. R. (2016). "Super-quenching" state protects Symbiodinium from thermal stress - Implications for coral bleaching. Biochimica Et Biophysica Acta (BBA) - Bioenergetics, 1857(6), 840-847. doi: 10.1016/j.bbabio.2016.02.002

- proposal for what triggers the bleaching

- The inhibition of PET and the consequent inhibition of organic carbon production (e.g. sugars) in the symbiotic Symbiodinium provide a trigger for bleaching.

Spalding, Mark, et al. "Mapping the Global Value and Distribution of Coral Reef Tourism." Marine Policy, vol. 82, 2017, pp. 104-113., doi:10.1016/j.marpol.2017.05.014. 
Storlazzi, C.D., Reguero, B.G., Cole, A.D., Lowe, E., Shope, J.B., Gibbs, A.E., Nickel, B.A., McCall, R.T., van Dongeren, A.R., and Beck, M.W., 2019, Rigorously valuing the role of U.S. coral reefs in coastal hazard risk reduction: U.S. Geological Survey Open-File Report 20191027, 42 p., https://doi.org/10.3133/ofr20191027..

- Facts about coral reefs and how they are monitored. Current projects on preservation and protection.

Sumich, J.L. 1996. An Introduction to the Biology of Marine Life, sixth edition. Dubuque, IA: Wm. C. Brown. pp. 255-269.

- Quote about coral algae symbiosis

Sweet, Michael, et al. "Coral Diseases in Aquaria and in Nature." Journal of the Marine Biological Association of the United Kingdom, vol. 92, no. 4, Jan. 2011, pp. 791-801., doi: $10.1017 / \mathrm{s} 0025315411001688$.

- Info on what is known about coral diseases, how they spread, cures

Thinesh, T., Meenatchi, R., Jose, P. A., Kiran, G. S., \& Selvin, J. (2019). Differential bleaching and recovery pattern of southeast Indian coral reef to 2016 global mass bleaching event: Occurrence of stress-tolerant symbiont Durusdinium (Clade D) in corals of Palk Bay. Marine Pollution Bulletin, 145, 287-294. doi: 10.1016/j.marpolbul.2019.05.033

- observation and analysis about susceptible and resistant corals and its symbiont affiliation

Todinanahary, Gildas Georges Boleslas, et al. "Community-Based Coral Aquaculture in Madagascar: A Profitable Economic System for a Simple Rearing Technique?" Aquaculture, Elsevier, 19 July 2016, www.sciencedirect.com/science/article/pii/S0044848616303611.

- Madagascar trying aquaculture and testing to see how viable it was

"UW Aerospace Engineer Part of \$1.7M Grant to Study Corals." UW News, 15 Nov. 2019, https://www.washington.edu/news/2019/11/15/uw-aerospace-engineer-part-of-coral-grant/.

- Efforts to save coral are pulling together researchers from multidisciplinary backgrounds

Ward, Jessica R, and Kevin D Lafferty. "The elusive baseline of marine disease: are diseases in ocean ecosystems increasing?.” PLoS biology vol. 2,4 (2004): E120.

doi:10.1371/journal.pbio.0020120

- Used quantitative use of normalized trends in the literature to investigate an ecological hypothesis.

- Increase in disease outbreak in some marine life

What is Coral Bleaching and What Causes It - Fight For Our Reef. (n.d.). Retrieved October 15, 2019, from https://www.marineconservation.org.au/coral-bleaching/.

- General info about coral bleaching

Zeitvogel, Karin. "World's Coral Reefs Could Be Gone by 2050: Study." Phys.org, Phys.org, 23 Feb. 2011, https://phys.org/news/2011-02-world-coral-reefs.html. 